\title{
Economies of scale in biogas production and the significance of flexible regulation
}

\author{
Nielsen, Lise Skovsgaard; Klinge Jacobsen, Henrik
}

Published in:

Energy Policy

Link to article, DOI:

10.1016/j.enpol.2016.11.021

Publication date:

2017

Document Version

Peer reviewed version

Link back to DTU Orbit

Citation (APA):

Nielsen, L. S., \& Klinge Jacobsen, H. (2017). Economies of scale in biogas production and the significance of flexible regulation. Energy Policy, 101, 77-89. https://doi.org/10.1016/j.enpol.2016.11.021

\section{General rights}

Copyright and moral rights for the publications made accessible in the public portal are retained by the authors and/or other copyright owners and it is a condition of accessing publications that users recognise and abide by the legal requirements associated with these rights.

- Users may download and print one copy of any publication from the public portal for the purpose of private study or research.

- You may not further distribute the material or use it for any profit-making activity or commercial gain

- You may freely distribute the URL identifying the publication in the public portal

If you believe that this document breaches copyright please contact us providing details, and we will remove access to the work immediately and investigate your claim. 


\title{
Economies of scale in biogas production and the significance of
}

\author{
flexible regulation
}

\author{
Lise Skovsgaard $^{1} \&$ Henrik Klinge Jacobsen \\ Technical University of Denmark, DTU Management Engineering, \\ Systems Analysis Division, 2800 Kgs Lyngby, Denmark
}

\begin{abstract}
Biogas production is characterised by economies of scale in capital and operational costs of the plant and diseconomies of scale from transport of input materials. We analyse biogas in a Danish setting where most biogas is based on manure, we use a case study with actual distances, and find that the benefits of scale in capital and operational costs dominate the diseconomies of increasing transport distances to collect manure. To boost the yield it is common to use co-substrates in the biogas production. We investigate how costs and income changes, when sugar beet is added in this case study, and demonstrate that transport cost can be critical in relation to co-substrates. Further we compare the new Danish support for upgraded biogas with the traditional support for biogas being used in Combined Heat and Power production in relation to scale economies. We argue that economies of scale is facilitated by the new regulation providing similar support to upgraded biogas fed into the natural gas grid, however in order to keep transport costs low, we suggest that the biogas plants should be allowed to use and combine as many co-substrates as possible, respecting the sustainability criteria regarding energy crops in Danish legislation. Keywords: Biogas; economies of scale; regulation; flexibility, biogas input; modelling; value chain
\end{abstract}

\section{Highlights:}

\section{${ }^{1}$ lskn@dtu.dk}


- For Denmark we find economies of scale in biogas production based on pure manure

- Adding sugar beet outweigh economy of scale due to increased transport costs

- We investigate the main risks associated with input prices, yield and output prices

- Biogas fed into the gas grid should receive similar support as directly used in CHP

- Regulation should allow large biogas plants with few restrictions on co-substrates

\section{Introduction}

Denmark has a long tradition for biogas production; and since the Energy crisis in 1973 initiated the building of the first biogas test plants, biogas production have increased in Denmark in varies tempi (Raven and Gregersen, 2007). Biogas production is focused on using domestic resources to generate renewable energy along with reducing environmental damage from waste products in agriculture, industry and households. In Denmark the primary input is manure with various co-substrates added to boost the yield, the development in biogas production have been supported through R\&D projects, temporary investment grants and support connected to the biogas output. The scale of plants have varied from decade to decade with focus on farm scale plants, then centralised plants and afterwards a revival of farm scale plants (Geels and Raven, 2007). Focus in biogas production has also changed through time from energy production to waste management, nutrients distribution, and green-house-gas reduction and lately back to energy production, where the newest development is towards centralised plants. Traditionally cosubstrates have been waste products from the agricultural sector such as e.g. slaughterhouse waste, which the biogas plants were paid to receive. Today these recourses are already in high demand with rising prices and new biogas plants will have to find other resources. (Geels and Raven, 2007).

Earlier studies have already found economies of scale in biogas production e.g. (Jacobsen et al., 2013; Nielsen and Hjort-Gregersen, 2002; Raven and Gregersen, 2007), and while the collection of resources requires transport over longer distances, driving up unit costs of inputs (Mafakheri and Nasiri, 2014), economies of scale for capital expenditures (capex) drives unit costs down. Walla and Schneeberger, (2008) look into the optimal size of a biogas plant supplying a combined heat and power plant (CHP) and find that the increased costs of transporting silage maize is offset by the benefits of scale in terms of capital costs and generation efficiency. We extend this analysis to larger plant size and examine a similar 
co-substrate (sugar beet) for which there is a specific resource mapping in relation to our case location, distances are however long illustrating the consequences of high transport distances.

Support for biogas in Denmark does not vary with scale in contrast to e.g. in Austria and Germany (Brudermann et al., 2015; Lantz et al., 2007).However, until recently support was only provided to biogas used in local CHPs limiting the biogas production to fit the heat demand for the connected CHP. Since 2014 it has been possible to upgrade the biogas to biomethane for the extensive natural gas net and receive a similar support as for the CHPs. The specific aim of this paper is to determine whether the new Danish support for upgraded biogas allows the scale effects to be realised, compared to the traditional support for biogas being used in Combined Heat and Power production.

We therefore consider larger scales compared to earlier studies (Walla and Schneeberger, (2008) and a situation with manure as the primary input resource and allow the choice of upgrading biogas to the natural gas grid. Scale effects for Denmark reported in (Jacobsen et al., 2013) and (Skovsgaard and Klinge Jacobsen, 2015) indicated that economies of scale could be identified in some cases for biogas plants, but adding sugar beet did not provide clear results with respect to scale. We investigate this further and consider whether the current Danish regulation provides the incentives to exploit the economies of scale, and which policy changes that can be affecting this.

Section 2 documents the methodological modelling approach. In section 3, the results are presented starting with scale effects in the $100 \%$ manure case and proceeding with the addition of sugar beet as a cosubstrate which facilitates a higher yield, but also adds costs.

Section 4 performs a sensitivity analysis of the key parameters such as yield, sugar-beet prices and transport distances. Section 5 discusses the risk elements that are revealed by the sensitivity analysis and identified due to the regulatory risks. In section 6, the results for economies of scale, earnings with cosubstrates and risk elements are combined for their regulatory implications and policy advice. Finally, section 7 draws the main conclusions.

\section{Methodology and model}

Based on a case study of an area in Denmark, we compare the two opposing scale effects for three specific sizes of a biogas plant. Like (Delzeit and Kellner, 2013), we include transport costs for manure, cosubstrate (sugar beet) and the output (digestate). We extend our analysis to larger scale and include the 
option of upgrading to the gas grid, economies of scale is also included in the investment costs for upgrading. We use an excel model to calculate the costs of input collection, biogas production and cleaning or upgrading for further use. Revenues from the operation are based on the gas prices plus subsidies that can be obtained depending on various choices for supplying the biogas output to a local combined heat and power unit (CHP) or to the natural gas grid. The approach is to focus on private profitability regarding the choice of scale and input composition.

Cost data are estimated from Danish historical data, and transport costs are calculated on the basis of an actual location in Northern Jutland in an area, where manure is found in large amounts so it is suitable for large-scale biogas plants. The applied biogas yields are the results of actual experiments on co-digestion conducted as a part of the Biochain project (see Acknowledgements), the choice of co-substrate (sugar beet) is therefore dependent on the availability of consistent data within the project. In order to comply with the issue of case specificity we conduct a sensitivity analysis, and this confirms the importance of specific co-substrate availability (transport cost), price and yield assumptions, which is supporting our conclusions on the importance of regulatory flexibility with regard to co-substrate choice.

\subsection{The model set-up}

The model is used to calculate total costs for the biogas production based on required input amounts for each scale of operation. We examine scale effects on total costs and income both with a production entirely based on (pig) manure as input as well as the cost and income effects of adding a co-substrate (sugar-beet) to boost the biogas yield.

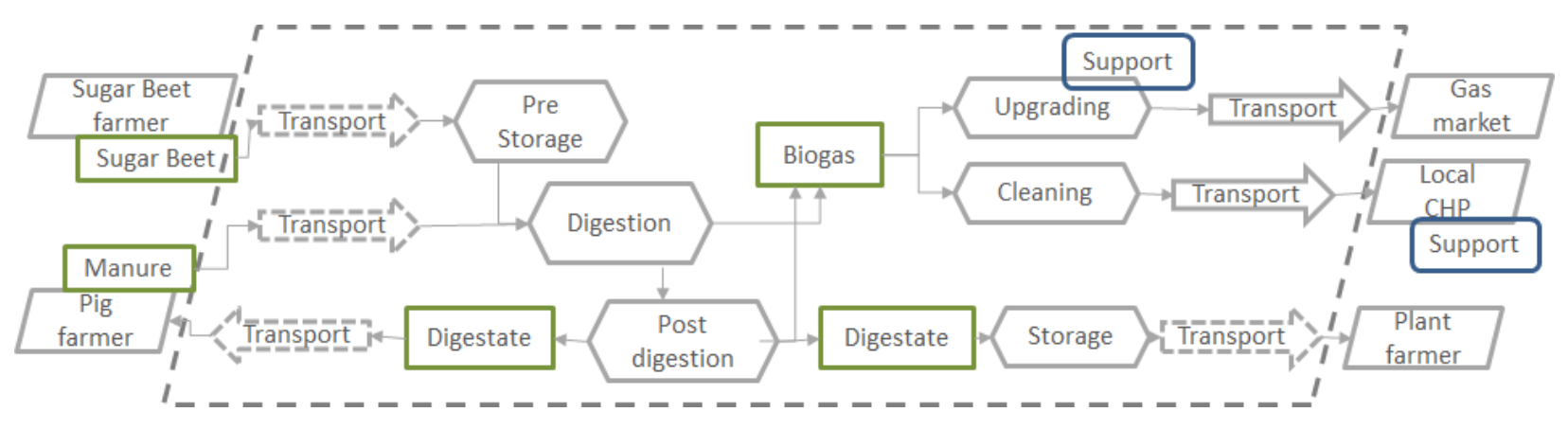

Figure 2-1: Economic flow chart

The value chain is depicted in Figure 2-1, where the dotted parallelogram encases the economic work space for the biogas plant, and thereby the costs and income which is included in the calculations. Manure 
and sugar beet is bought from the farmers at a given price and then transported to the plant. Here the input is mixed and digested resulting in two products; the digestate, which is returned to the farmer, and biogas, which is either upgraded for the gas market or cleaned and sold to the local CHP.

Three different plant sizes are investigated. Small (110) with a capacity of 110,000 tonne of biomass input p.a., Medium (320) with a capacity of 320,000 tonne and Large (500) with a capacity of 500,000 tonne. Arguments for this choice of size can be found in the appendix in the section on key data.

Three different cases of input mix of pig sludge (PS) and sugar beet (SB) in the feedstock are analysed for all scales: A case with manure only, PSSB-0: 100\% PS, 0\% SB and two cases where sugar beet is added: PSSB-12.5: 87.5\% PS, 12.5\% SB and PSSB-25:75\% PS, 25\% SB. The cases were selected on the basis of current and future Danish regulation (to achieve biogas support, the permitted maximum percentage of energy crops is 25\% until 2017 and 12\% subsequently ${ }^{2}$ (Danish Energy Agency, 2012)

This gives nine different results to analyse and compare.

To compare the scenarios, the total net income, $T N I\left(p_{k}, \mathrm{M}_{j}, M_{k}, \mathrm{r}_{j}, \mathrm{j}, \mathrm{k}\right)$ for the different scenarios has to be found.

$$
\operatorname{TNI}\left(p_{j}, p_{k}, M_{j}, M_{k}\right)=\operatorname{TI}\left(p_{k}, p_{\text {manure }}, M_{k}, M_{\text {manure }}\right)-T C\left(M_{j}, M_{k}\right)
$$

Where $\operatorname{TI}\left(p_{k}, p_{\text {manure }}, M_{k}, M_{\text {manure }}\right)$ is the total income for the plant as a function of the price of output $k, p_{k}$, the mass of output $k, \mathrm{M}_{k}$ and the price and mass of the input manure. $\operatorname{TC}\left(M_{j}, M_{k}\right)$ represent the total costs as a function of the mass of biomass input, $j$, and the mass of output $k$. The sets $J$ and $K$ represent the set of input biomass (manure and sugar beet) and the set of output (gas and digestate).

\subsection{Total costs}

Total costs are expressed as:

\footnotetext{
${ }^{2}$ In the experimental study it was decided to use $12,5 \%$ and not the regulated $12 \%$, (Boldrin et al., 2016).
} 


$$
\begin{aligned}
T C\left(M_{j}, M_{k}\right)= & C_{\text {input }}\left(M_{\text {Sugar Beet }}\right)+C_{\text {trans }}\left(M_{j}, M_{\text {digestate }}\right)+C_{\text {opex }}\left(M_{j}\right)+C_{\text {capex }}\left(M_{j}\right) \\
& +C_{\text {output related }}\left(M_{k}\right)
\end{aligned}
$$

Where $C_{\text {input }}\left(M_{\text {Sugar Beet }}\right)=p_{\text {sugar beet }} \cdot M_{\text {Sugar Beet }}$, input- and output products are marked in green in Figure 2-1. The pricing of manure is, however, closely linked to the output price of digestate and, therefore, input costs for manure are integrated in the income equation, this is further explained in Appendix A.

All capital expenditures are annuitized at a 5\% discount rate with a depreciation period of 20 years.

\section{Capital expenditures (Capex) and Operational Costs (Opex)}

$C_{\text {opex }}\left(M_{j}\right)$ and $C_{\text {capex }}\left(M_{j}\right)$ are the investment and operational costs related to the actual production of biogas. In Figure 2-1, this is depicted as the costs related to pre-storage, digestion and post digestion i.e. $C_{\text {capex }}\left(M_{j}\right)$ includes all necessary plant specific investment costs in storage tanks, digesters, buildings, land, process heaters, control systems, advisory services and so on. $C_{\text {opex }}\left(M_{j}\right)$, on the other hand, encompasses all operational costs directly related to the plant, i.e. manpower, fuel costs for process heating, maintenance and running costs (Ea Energianalyse, 2014).

Capex and Opex are estimated from data on the estimated costs for projected plants applying for investment support in 2012 in Denmark combined with model plants from the same period in time. The data estimations have been calculated from the equation of the best-fitting estimated trend line on these data, and are implemented in the model as the primary cost for Capex and Opex respectively.

\begin{tabular}{l|lllll}
\hline & Nr. of Plants & Data year & Size Interval in $t / y$ & Equation in Euro/t/y & $R^{2}$ \\
\hline Capex & 15 & 2012 & $42.000-491.000$ & $\mathrm{Y}=115,4-6 \ln (\mathrm{x})$ & 0.40 \\
Opex & 12 & 2012 & $42.000-491.000$ & $\mathrm{Y}=9.87-0.46 \ln (\mathrm{x})$ & 0.33 \\
\hline
\end{tabular}

Table 2-1: Details on the cost estimates

In the cases where sugar beet is added to the process additional Capex and Opex related to sugar beet are included. 
To calculate the input cost for sugar beet pulp, a price of 27.46 Euro/tonne is used. The price is given by SEGES $^{3}$ (Abildgaard, 2015) and the price is estimated for sugar beet pulp/sliced sugar beets.

Capex and Opex related to output is included in the output-related costs.

\section{Output related costs}

$C_{\text {output related }}\left(M_{k}\right)$ costs are depicted in Figure 2-1 and include cleaning, upgrading, transport and storage. The output related costs are all additional costs related to the output, investment in upgrading equipment or biogas cleaners and the related operational costs along with gas compression costs. Also within the output related costs there are scale effects, see more in appendix A. In case PSSB-25, where $25 \%$ of sugar beet is added, not all digestate can be returned to the animal farmers and, therefore, the remaining digestate has to be stored on site and transported separately to neighbouring plant farmers. These additional capital, operational and transport costs are also included in the output related costs.

The output related costs are found separately from several sources and added together. Further information on these data can be found in the section on key data in the appendix.

\section{Transport: Collection costs and density of resources}

$C_{\text {trans }}\left(M_{j}, M_{\text {digestate }}\right)$, transport costs are the sum of transport costs for transporting input biomass to the biogas plant (PS and SB) and returning the digestate to farmers.

Transport costs are calculated on the basis of available data given by SEGES and typical $\mathrm{km}$ and load costs. We use the specific locations of the farms and calculate the necessary travel distance to collect the manure using concentric circles around the biogas plant modelling the estimated distance as a function of the radius (i.e. the distance from the plant). We assume that already treated manure/digestate is returned to the farmers on the same trip. Transport distances, type of vehicle, loading costs, etc. are taken into account as in (Walla and Schneeberger, 2008); the kilometre cost correspond to $62-81 \%$ of total transport costs; further information on the transport modelling can be found in (Boldrin et al., 2016).

\footnotetext{
${ }^{3}$ SEGES is an independent consultant firm with focus on agriculture located in Denmark
} 
Increasing the scale of operations results in longer distances to collect, but it varies substantially between the manure and the sugar beet. The plant is purposely placed in a high manure density area, which in itself reduces the distances and, thereby, transport cost for manure, the average distance is calculated to be in the interval of 5-10 kilometre depending on scale and share of manure input. Furthermore, transport cost can be considered as shared with the output, digestate, as it is assumed that this is returned in the same trucks that deliver the manure. This is common practice in Denmark as manure is the most substantial part of the biomass input and the return of the digestate to the farmer is an integrated part of the value chain (Raven and Gregersen, 2007) in contrast to some biogas production plants in, for example, Austria and Germany (Brudermann et al., 2015; Lebuhn et al., 2014).

Sugar beets, on the other hand, are not produced in vast amounts close to the model plant, which results in longer transport distances; here the average distance is calculated to be in the interval of 22-70 kilometre Furthermore, transport costs are "doubled" so to speak, as it is assumed that the sugar beet trucks drive empty in one direction. Due to this long transport distance for sugar beet, particularly in the PSSB-25 cases, a maximum distance assumption has been added to the model data with the larger scales. The assumption is that all sugar beet demand can be covered within the distance of $80 \mathrm{~km}$ - even when the data say otherwise. This constraint makes sense as sugar beet would normally not be transported more than $40 \mathrm{~km}$ (Abildgaard, 2015). The effect of this can be seen in the final results, but it does not affect the overall conclusions.

\subsection{Total income}

Total income is determined by price and quantity of the three products marked in green in Figure 2-1 (biogas, manure and digestate), support (marked with blue) is an integrated part of the price. Income is expressed as:

$$
\begin{gathered}
\operatorname{TI}\left(p_{k}, p_{\text {manure }}, M_{k}, M_{\text {manure }}\right)=\sum_{k \in K} p_{k} M_{k}-p_{\text {manure }} \cdot M_{\text {manure }} \\
=I\left(p_{\text {gas }}, M_{\text {gas }}\right)+N I\left(p_{\text {Digestate }}, M_{\text {digestate }}\right)
\end{gathered}
$$

Where $M_{k}$ is the mass of output $k$ resulting from using a specific mix of biomass 1 and 2 from the set $J$. The digestate $M_{\text {digestate }}$ is the residual after gasification 
Data on biogas yield, the digestate price and biogas prices can be found in the appendix in the section on key data.

Income from digestate is defined as a net income where the input cost from manure is deducted from the income from sold digestate.

$$
N I\left(p_{\text {Digestate }}, M_{\text {digestate }}\right)=p_{\text {digestate }} M_{\text {digestate }}-p_{\text {manure }}^{\text {input }} \cdot M_{\text {manure }}
$$

This is due to a trade principle with the farmers, where digestate buyers and manure sellers in most cases are the same. Therefore, the net income expresses the actual value of the digestate.

Biogas income is defined as

$$
\begin{gathered}
I\left(p_{\text {gas }}, M_{\text {gas }}\right)=p_{\text {gas }} \cdot M_{\text {gas }}, \text { where } \\
p_{g a s, U P}=p^{N G, U P}+p^{g}+S_{g a s, U P} \text { and } p_{\text {gas }, C H P}=p^{N G, C H P}+S_{g a s, C H P}
\end{gathered}
$$

I is income, $\mathrm{p}$ is price, $\mathrm{M}_{\mathrm{gas}}$ is the amount of $\mathrm{m}^{3}$ biomethane. $\mathrm{P}_{\mathrm{gas}}$ UP is the price of upgraded biogas, $p^{N G}$, price of natural gas (here referred to as the basis price), $p^{g}$, a potential green value and $\mathrm{S}$ equals the support value, depending on where the gas is delivered (at a local CHP or upgraded for the natural gas net).

Notice that all support for the biogas production is concentrated on the biogas yield.

\section{Biogas price}

The biogas price differs depending on whether the biogas is upgraded or sent directly to a local CHP.

$$
p_{g a s, U P}=p^{N G, U P}+p^{g}+S_{g a s, U P} \text { and } p_{g a s, C H P}=p^{N G, C H P}+S_{g a s, C H P}
$$

In this model, it is assumed that $p^{N G, U P}=p^{N G, C H P}$ and $S_{g a s, U P} \approx S_{g a s, C H P}$. In real life, both $p^{N G, U P}$ and $p^{N G, C H P}$ will most often be a function of the natural gas price, where it can be expected that the 
upgraded price will be closer to the actual market price, whereas the CHP-price is expected to be lower if biogas is the only input fuel to the CHP. This is because the CHP has a seasonal fuel demand and biogas production is almost the same throughout the year. Furthermore the $p^{N G, C H P}$ is pushed down by a looser regulation on the use of cheap biomass and the heat regulation setting a cap on the biogas price (Lybæk, 2014; Tafdrup, 2010).

The green value $p^{g}$ is a green certificate which is sold along with the biogas. There is no actual support attached to this certificate, however it can be exchanged for $\mathrm{CO}_{2}$-quotas and then it further represents the green value that some may be willing to pay for.

In the model $S_{g a s, U P} \approx S_{g a s, C H P}$ as we assume that all support is handed to the biogas producer. In real life it is probable that most support is given to the biogas plant when the gas is upgraded as support is paid directly to the upgrading facility, which often has the same owner as the biogas producer (Danish Parliament, 2012). Support for biogas used in a local CHP, on the other hand, is less likely to be entirely handed over to the biogas plant as the support is only paid indirectly through a tax reduction on fuel for heat and support to the power production. In many cases the CHP does not have the same owner as the biogas plant.

\subsection{Upgrade vs. direct use}

The biogas plant can send the biogas to a local CHP or upgrade to biomethane and connect it to the gas grid. With larger scales it becomes more relevant to upgrade due to the limited demand for the heat output from the CHP. Both choices involve additional capital and operational expenditures, where upgrading is the more expensive choice.

The choice between upgrading and local use is determined by actual conditions at the plant position. In the case considered here there is a local CHP using approximately 3.5 mill $\mathrm{m}^{3}$ biogas per year. Therefore, the model determines whether to upgrade or not based on the expected biogas yield. If yield $<3.5 \mathrm{mill}^{3}$ biogas p.a., the biogas is cleaned and sent to the local CHP otherwise all the biogas is upgraded and sent to the natural gas net. 
Imbedded in this model decision is the assumption, that all gas is demanded when it is produced. In the case of upgraded biogas, there is unlimited storage and a larger market which can match the demand. In the case of local use, there is a higher risk that demand will not match the supply - for example during the summer season when demand for heat is lower. The larger the biogas production, the higher the risk that a local CHP will not be able to use all the biogas efficiently; therefore, upgrading can reduce the risk of insufficient demand, a risk that must be expected to increase with scale.

\section{Results}

The three scales of operation are compared: Small 110,000 tonnes of input p.a.; Medium $(320,000)$ and Large $(500,000)$ each denoted by 110,300 and 500. We are looking for scale effects and the most profitable case. To identify pure scale effects, we start with the simplest case - $100 \%$ manure.

\subsection{Costs and scale, $100 \%$ manure}

First costs are investigated in the case of 100\% manure. As seen in Figure 3-1 and

Figure 3-2 there is a tendency towards economies of scale although the total unit cost only reduces by $6 \%$ while the plant becomes almost five times as large, it is clear there is a trade-off between rising transport costs (almost 50\%) and falling investment and operational costs (approximately 18\%)
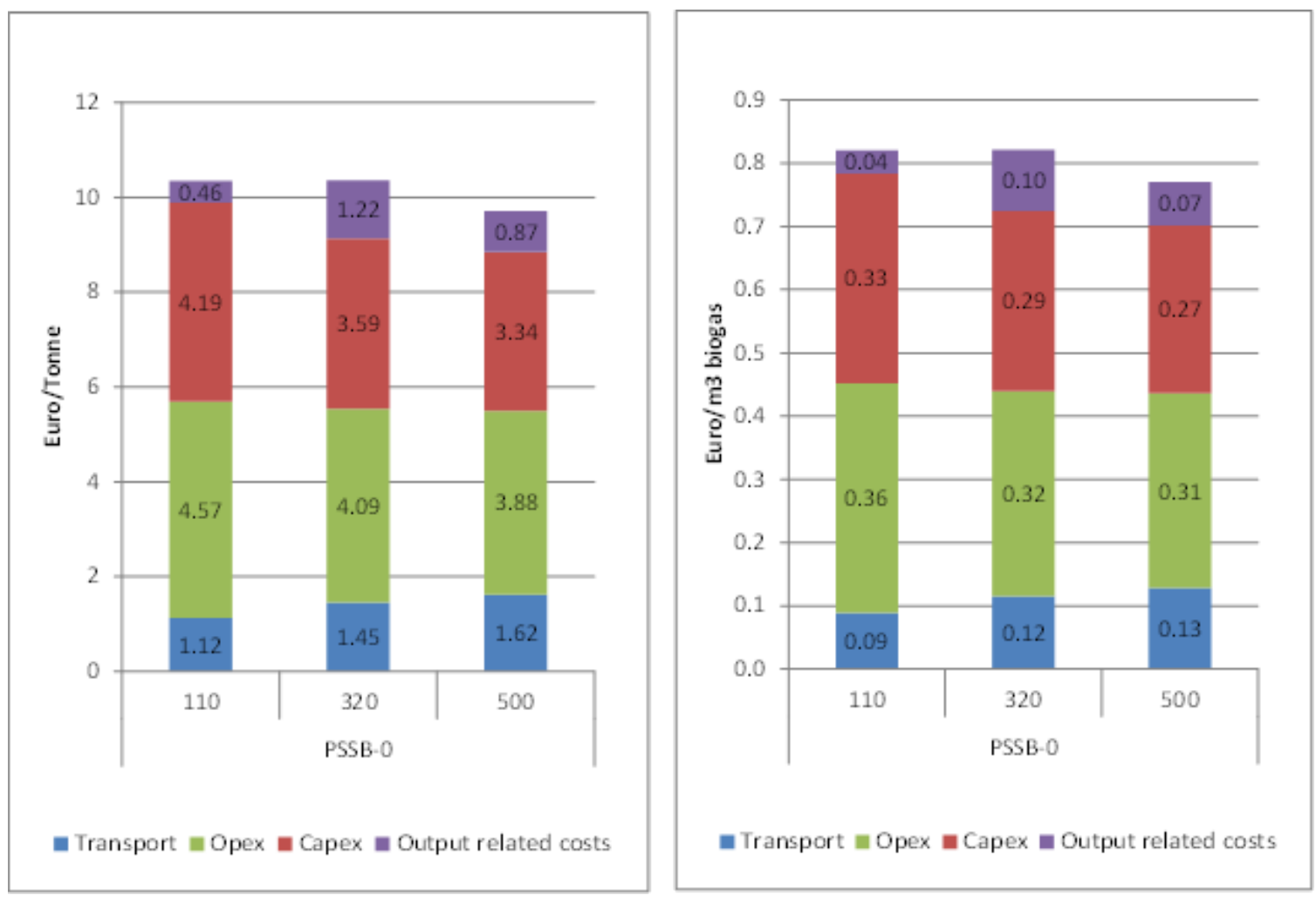
It is also clear that output-related costs shift significantly between the three different scales. The first shift from small to medium size is the result of a technology shift from gas cleaning to upgrading, while the second shift is due to economies of scale within the upgrading technology.

\subsection{Adding sugar beet}

It is common to add co-substrates in order to boost the manure based biogas yield. To investigate whether the benefits from the higher yields outweigh the additional costs related to sugar beet, we therefore examine two cases where $12.5 \%$ and $25 \%$ sugar beet is added as co-substrate.

Scaling up the biogas plant reduces capital and operational costs per unit of input for all input compositions with $16-18 \%$

Total costs in Euros/m3 are depicted in Figure 3-3, from which it becomes clear that the extra costs related to sugar beet are not outweighed by the sugar beet related boost to the biogas. Total cost per tonnes of input more than doubles when $25 \%$ sugar beet is added and the main contributor to this increase is the purchasing cost of sugar beet that determines the level of costs, but also the rising transport costs is an important factor. Both elements reveal the importance of securing low cost co-substrates and collecting the resources available close to the plant. When looking for scale effects in the sugar beet cases, we find an almost stable unit cost in all three different plant sizes. Thus there are no clear signs of economies of scale as found in the $100 \%$ manure case. 


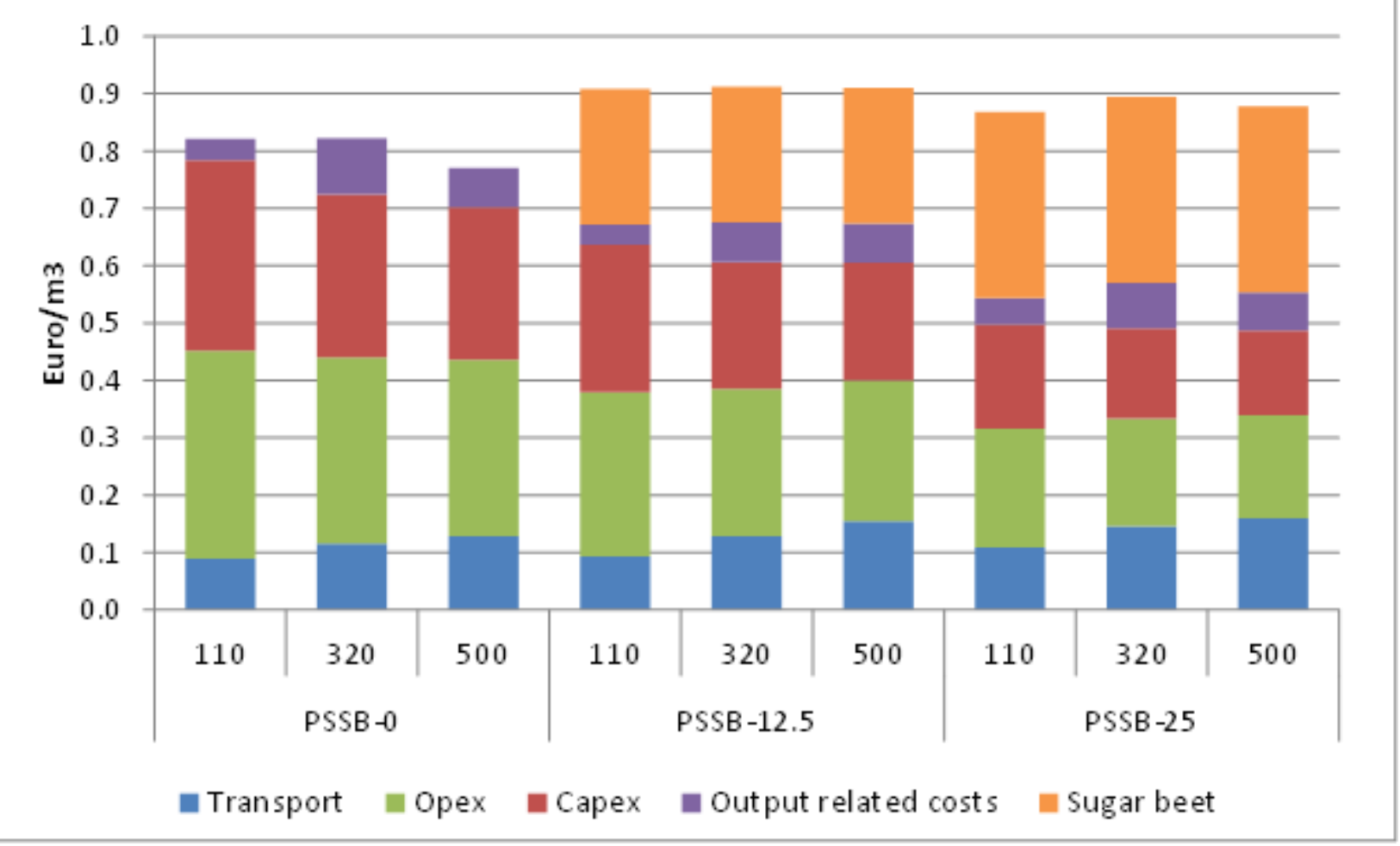

Figure 3-3: Cost distribution when sugar beet is added, Euro/m3 biogas

The balance between, in particular, increased transport costs and the reduced capital and operational costs results in almost equal total unit costs for the large and small-scale in the PSSB-25 case, this is due to a combination of several counteracting effects. We find positive scale effects regarding the upgrading facility in the shift from a medium to a large-scale plant, while the 110,000 tonne case does not involve upgrading resulting in lower output related costs.

At the same time does the unit costs associated with transport increase so much that they exceeds capex in the large case. Along with the increased output related costs this outweighs the entire scale benefit from opex and capex.

\section{Transport costs; adding sugar beet}

Focusing on the transport costs, we find that sugar beet availability in the local area is dispersed and requires longer transport distances than the manure. Hereby, the total transport costs per unit increase by almost $150 \%$ when moving from zero to $25 \%$ sugar beet (represented by the vertical arrow) in Figure $3-4$. The figure presents the summed transport costs in all three cases of input mix and the cost of manure transport and sugar beet transport in the PSSB-12.5 case. For the sugar beet cases, the unit cost also 
increases with scale (represented by the horizontal arrow). The graph clearly shows that sugar beet transport costs increase faster than manure transport costs. Furthermore, as the level of transport cost is higher, the absolute increase in transport costs from 110-500,000 tonnes results in a larger contribution to diseconomies of scale than for the zero sugar beet case. However even though transport costs increase with scale, they only account for $17-18 \%$ of the total costs, even in the large scale cases. This cost share seems quite small compared to other analyses such as (Yabe, 2013), who finds that transport costs account for around $56 \%$ of the yearly costs of biogas plants in Japan.

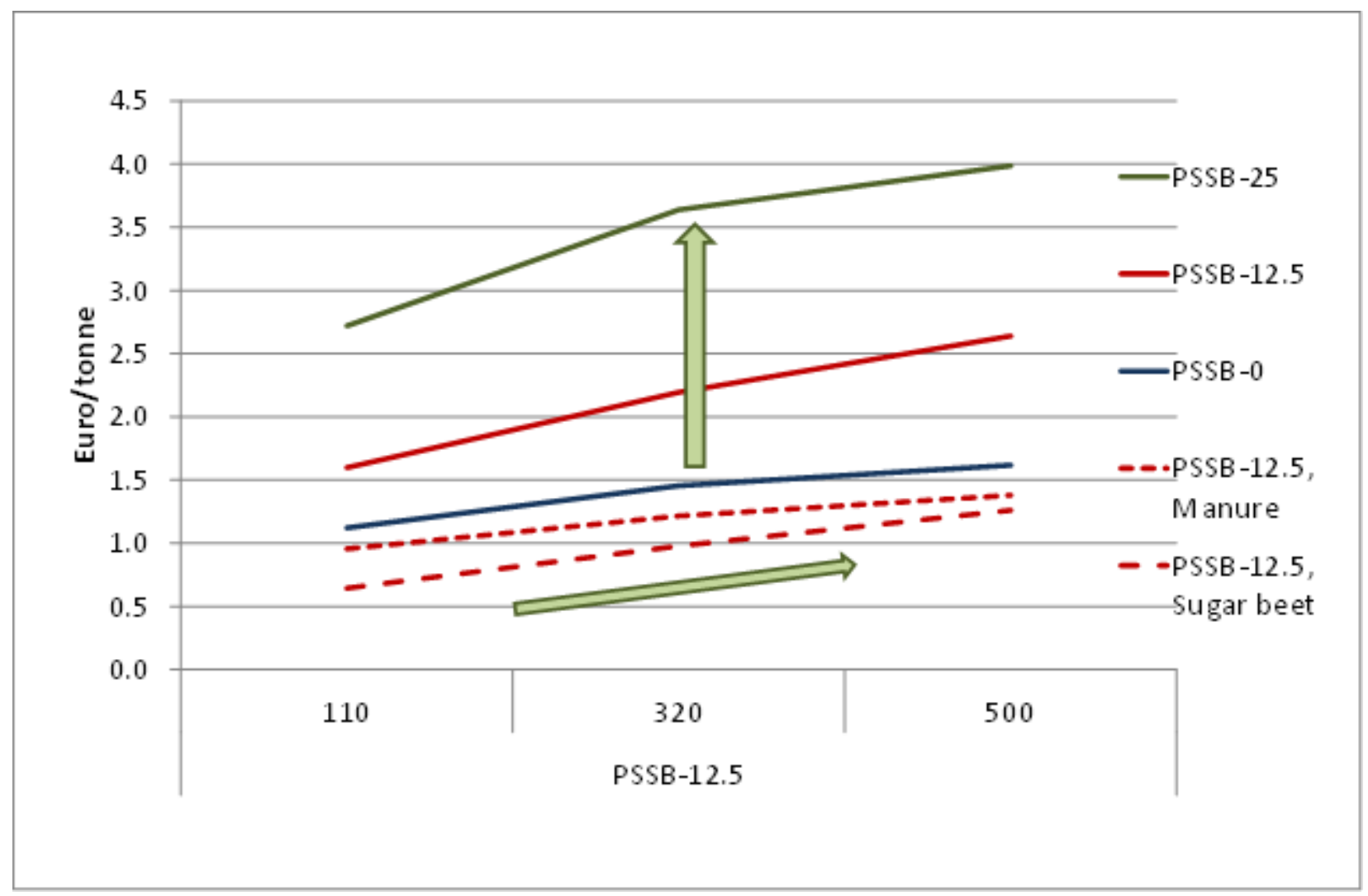

Figure 3-4: Transport costs in Euro/tonnes of input

\subsection{Total costs and scale effect results}

Only based on the graphs it is clear, that costs increases - in line with the amount of sugar beet that is added to the slurry. Furthermore it is difficult to detect a clear scale effect in the mixed manure and sugar beet cases. Purely based on the costs, the options with 110,000 tonnes annually seem best in the sugar beet cases. However, as the income from the upgraded biogas is slightly higher, the options with upgrading may become more attractive considering the fact that the cost difference is marginal between scales. 


\section{Scale effect results:}

When summarising the cost results we can say that:

- A unit cost reducing effect results from upscaling biogas plant size from 110,000 tonnes of annual inputs to 500,000 tonnes (together capex and opex per unit are reduced by 16-18\%).

- A unit cost increasing effect results from scaling on transport costs (an increase of $45 \%$ for manure input and 47-65\% for sugar beet input).

- The net effect (trade-off) results in almost equal costs per unit for all sizes in the PSSB-12.5 case and a small increase in the medium-sized cost in the PSSB-25 case, where the small and large-scale unit costs are otherwise almost the same. The benefit of upscaling to 500,000 tonnes (biogas plant + upgrade capex) is outweighed by the increase in transport costs for both inputs and outputs.

\subsection{Income}

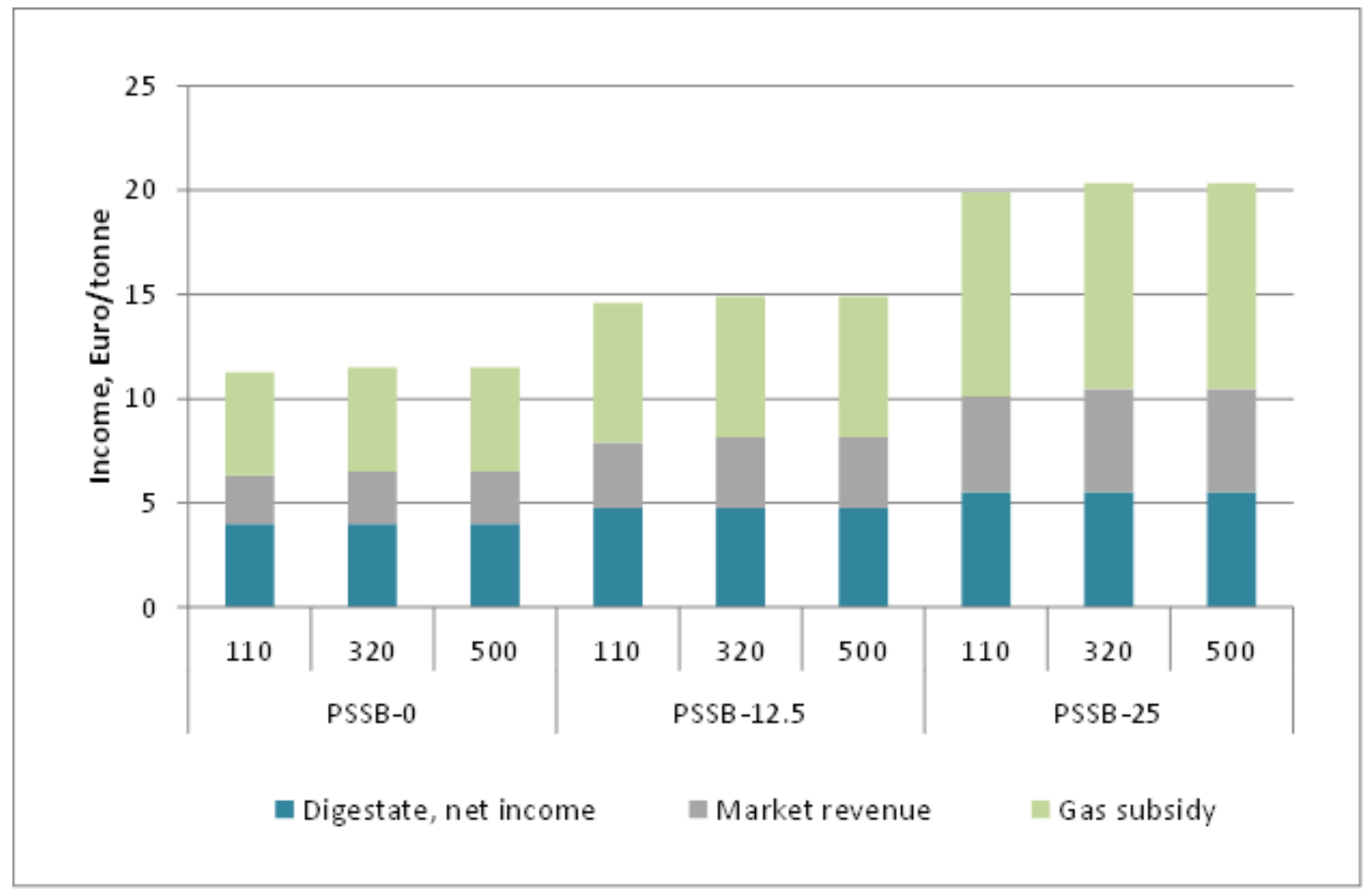

Figure 3-5: Income distribution

The biogas plant earns its income from both the treatment of manure - converting it to digestate, and from biogas. 
Net income from digestate accounts for around one third of total income. The basis price of the biogas accounts for around $20-25 \%$ of the income, and this is only slightly higher in the cases where the biogas is upgraded (in cases with medium and large-scale production). The remaining income can be assigned to the biogas support.

Consequently, around two thirds of the income is dependent on the level of biogas subsidies and, thereby, a high biogas yield.

\subsection{Net earnings results}

Based on existing subsidies, price assumptions for inputs and outputs and the production technology, the only viable input composition is PSSB-0, i.e. $100 \%$ manure, with the most viable size being the largescale production plant. The finding that the large-scale plant is the most profitable is in line with the findings for new Danish plants based on manure examined in (Jacobsen et al., 2013), (table 4.16 and 4.17) where a plant size of 360,000 tonnes is more profitable than smaller sizes.

\begin{tabular}{ll|ccccccccc}
\hline \multirow{2}{*}{ Euro/tonnes } & & \multicolumn{3}{|c}{ PSSB-0 } & \multicolumn{3}{c}{ PSSB-12.5 } & \multicolumn{3}{c}{ PSSB-25 } \\
\cline { 3 - 11 } Revenues & Biogas & 2.31 & 2.49 & 2.49 & 3.13 & 3.37 & 3.37 & 4.58 & 4.93 & 4.93 \\
& Support & 4.94 & 4.99 & 4.99 & 6.70 & 6.76 & 6.76 & 9.79 & 9.89 & 9.89 \\
& Digestate & 4.02 & 4.02 & 4.02 & 4.77 & 4.77 & 4.77 & 5.53 & 5.53 & 5.53 \\
\hline Costs & Transport & 1.12 & 1.45 & 1.62 & 1.60 & 2.19 & 2.64 & 2.72 & 3.64 & 3.99 \\
& Capex & 4.19 & 3.59 & 3.34 & 4.39 & 3.77 & 3.52 & 4.54 & 3.92 & 3.68 \\
& Opex & 4.57 & 4.09 & 3.88 & 4.87 & 4.39 & 4.18 & 5.18 & 4.69 & 4.48 \\
& Output related & 0.46 & 1.22 & 0.87 & 0.61 & 1.18 & 1.16 & 1.15 & 1.99 & 1.67 \\
& Sugar beet & - & - & - & 4.04 & 4.04 & 4.04 & 8.09 & 8.09 & 8.09 \\
\hline Net-income & & 0.93 & 1.15 & 1.79 & -0.91 & -0.67 & -0.64 & -1.77 & -1.98 & -1.56 \\
\hline
\end{tabular}

Table 3-1: Revenues, costs and net-income, Euro/tonnes

Adding sugar beet to the production increases the biogas yield, although not enough to compensate for the additional costs related to the sugar beet, so that the net earnings become negative. For the PSSB-12.5 case, the result is close to break-even between investing or not.

The price of sugar beet is around 4.5 times the price of manure. The higher yield from adding sugar beet leads to increased earnings in the sugar beet cases which are almost high enough to achieve positive net earnings for the $12.5 \%$ sugar beet case, but the yield in the case with $25 \%$ sugar beet is not high enough to make up for the increased cost due to the higher input costs of sugar beet. This is not the result of increased transport costs, but rather the high price of sugar beet. A $30 \%$ reduction in the price of sugar 
beet could make all cases profitable. The price of sugar beet is, therefore, a key assumption and sensitivity has been conducted in the following section.

Biogas yield is also a critical factor for profitability. The negative results for the sugar beet cases are caused by the unexpectedly relatively lower yields for the sugar beet cases. The yields would have had to be somewhat higher to make these options more economical than the $100 \%$ manure case. Sensitivity analysis in the next section also examines this variable.

\section{Sensitivity analysis}

In this paper, we use a case study to form a general picture on the potential for scale effects in biogas production and relate it to the current regulation, given the wish to expand biogas production in Denmark. We are aware, that some factors and assumptions in a case study will be case specific and subject to insecurity. We therefore perform this sensitivity analysis in order to get a picture of the importance of certain factors in relation to the net-income for a biogas plant. We have chosen to use a constant symmetric variation in the sensitivity analysis in order to be able to compare the importance of the investigated factors to each other. We then assess the probability of variation qualitatively.

We perform a sensitivity analysis on four factors related to net-income: sugar beet prices, transport costs, yield and the biogas subsidy. As previously discussed, sugar beet prices and transport costs can have a significant influence on the profitability of the biogas plant and, therefore, these costs are examined. Furthermore, yield and support are investigated due to the high income share from support, which entirely focuses on the biogas yield.

The sensitivity analysis is conducted with regard to the net-income where the factors in question are halved and increased by 50\%. This factor is chosen from the perspective of achieving substantial alterations in the results and in the same time sustains symmetry.

Table 4-1 presents a sensitivity analysis of transport costs for all three cases (PSSB-0, PSSB-12.5 and PSSB-25). As can be seen in most cases, a relatively large reduction/ or increase in transport distances is not enough to change the overall results regarding net-income. 


\begin{tabular}{l|ccccccccc}
\hline & \multicolumn{3}{|c}{ PSSB-0 } & \multicolumn{4}{c}{ PSSB-12.5 } & \multicolumn{3}{c}{ PSSB-25 } \\
& 110,000 & 320,000 & 500,000 & 110,000 & 320,000 & 500,000 & 110,000 & 320,000 & 500,000 \\
\hline Net-income & 0.93 & 1.15 & 1.79 & -0.91 & -0.67 & -0.64 & -1.77 & -1.98 & -1.56 \\
\hline $50 \%$ distance & 1.29 & 1.67 & 2.40 & -0.42 & 0.12 & 0.23 & -0.83 & -1.09 & -0.79 \\
$150 \%$ distance & 0.57 & 0.62 & 1.18 & -1.40 & -1.46 & -1.50 & -2.71 & -2.87 & -2.33 \\
\hline
\end{tabular}

Table 4-1: Sensitivity analysis on the transport distance, Euro/tonnes

In order to compare the importance of transport cost in relation to the sugar beet costs, a sensitivity analysis was conducted on sugar beet prices and plotted together with the transport distance as illustrated in Figure 4-1 below.

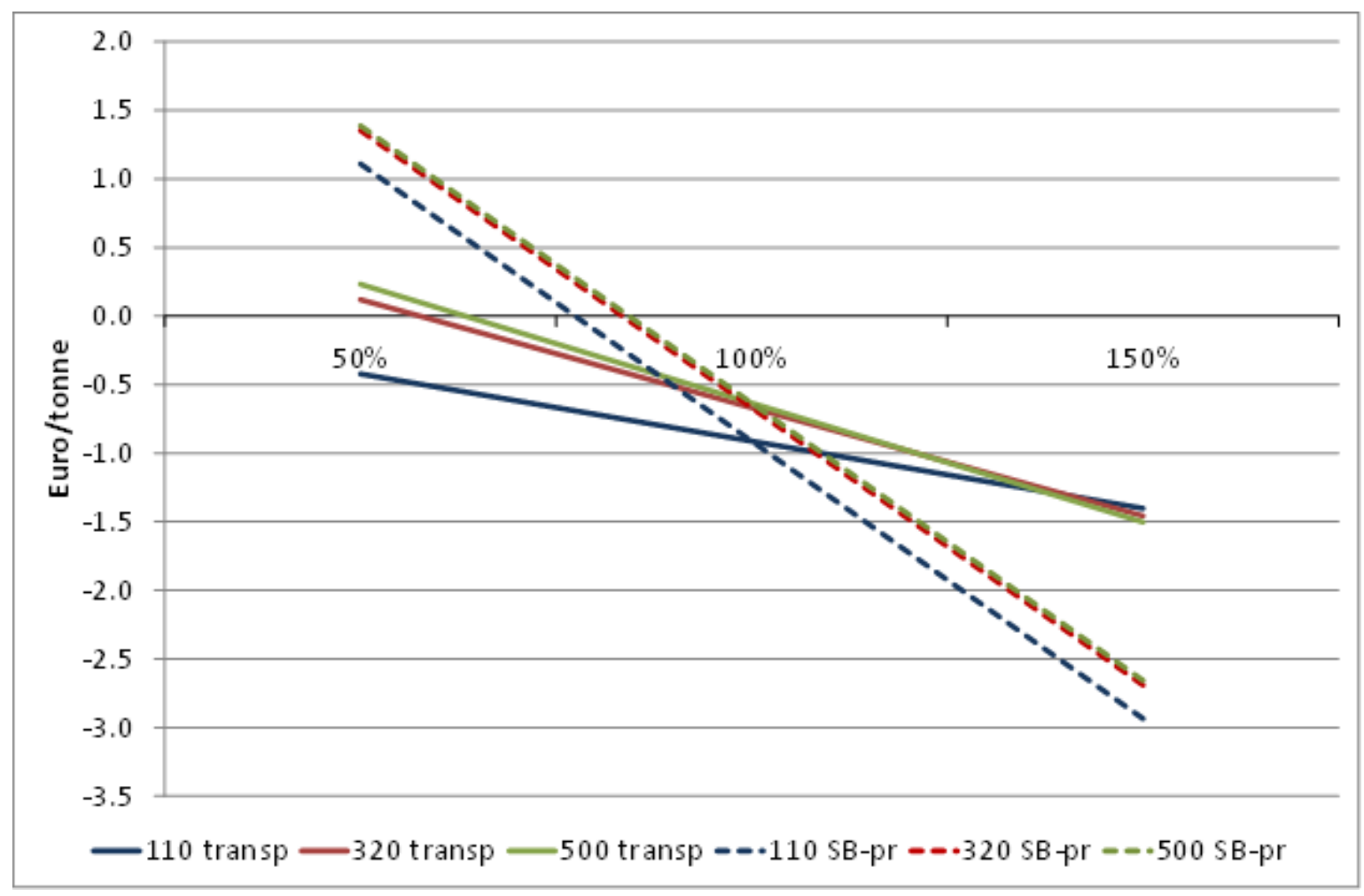

Figure 4-1: Sensitivity - Net income effect in the PSSB-12.5 case with changes in transport costs and sugar beet prices

While transport costs play a significant role, the sugar beet price, unsurprisingly, is an even more important factor regarding the net income result in the sugar beet scenarios. We find that while a $50 \%$ reduction in transport distance only just makes the business case positive in the larger cases, a 50\% reduction in the sugar beet price leads to a positive result for all sizes. It is, however, unrealistic to assume that the price of sugar beet will be halved, as the modelled sugar beet price is relatively close to production costs (Abildgaard, 2015). Transport costs, on the other hand, particularly for sugar beet, may be expected to be significantly lower in cases where sugar beet is used as substrate (Abildgaard, 2015). In the appendix, Figure B-1 presents the same sensitivity analysis for PSSB-25 with approximately the same 
result, although even a $50 \%$ reduction in transport distance is not enough to change the negative net income result.

Not only are costs important for the results, but also potential income in the form of biogas yield and biogas prices. When we compare the biogas yields used in this case study with what is actually produced annually at Danish biogas plants the yields generated in the cases with co-substrates seems relative low see for example (Jacobsen et al., 2014). When conducting the sensitivity analysis on the biogas yield and subsidy we find that a $50 \%$ increase in biogas yield improves profitability significantly in all cases. The best results are found in the PSSB-25 cases where net-income per tonne of biomass suddenly becomes larger for the PSSB-25 cases than for the PSSB-12.5 case for the large and medium-sized plants, and the higher yield compensates for the substantial increase in transport and sugar beet costs. Similar; only less pronounced results appears with changes in the biogas subsidy, also displayed in

Table 4-2. This is not surprising given, that the subsidy covers a smaller part of the income.

\begin{tabular}{l|ccccccccc}
\hline & \multicolumn{3}{|c}{ PSSB-0 } & \multicolumn{1}{c}{ PSSB-12.5 } & \multicolumn{3}{c}{ PSSB-25 } \\
Yield & 110,000 & 320,000 & 500,000 & 110,000 & 320,000 & 500,000 & 110,000 & 320,000 & 500,000 \\
\hline Net-income & 0.93 & 1.15 & 1.79 & -0.91 & -0.67 & -0.64 & -1.77 & -1.98 & -1.56 \\
\hline $50 \%$ yield & -2.63 & -1.71 & -1.42 & -5.53 & -5.01 & -5.37 & -8.55 & -8.91 & -8.48 \\
\hline $150 \%$ yield & 4.35 & 4.81 & 5.36 & 3.72 & 3.84 & 4.20 & 3.33 & 5.09 & 5.19 \\
\hline Support & & & & & & & & & \\
\hline $50 \%$ subsidy & -1.54 & -1.35 & -0.70 & -4.26 & -4.05 & -4.02 & -6.67 & -6.93 & -6.51 \\
$150 \%$ subsidy & 3.40 & 3.64 & 4.29 & 2.44 & 2.71 & 2.75 & 3.12 & 2.96 & 3.39 \\
\hline
\end{tabular}

Table 4-2: Sensitivity - net income effects with changes in the biogas yield and support

The importance of the factors on the input and output side are compared in Figure 4-2 through changes in net income when sugar beet prices are changed compared to changes in the yield.

The figure illustrates that even though the price of sugar beet has a significant influence on the net income, the level of biogas yield has an even greater effect.

It is also clear that net income increases less in the small-scale case. This is because the biogas yield is so high that it becomes necessary to invest in upgrading, even in the small-scale cases. In the appendix, Figure B-2 presents the same sensitivity analysis for the PSSB-12.5 case. 


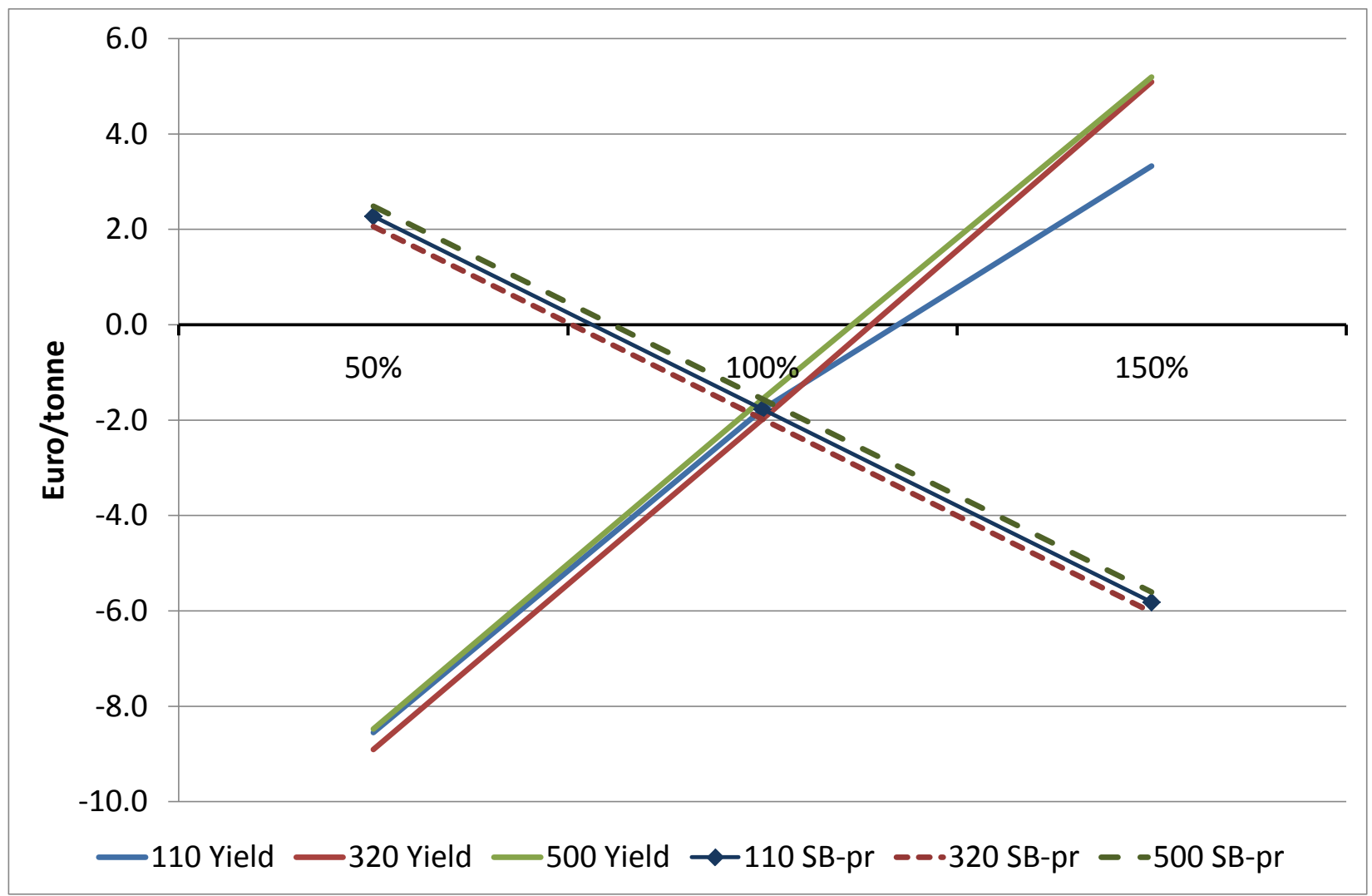

Figure 4-2: Sensitivity - Net income effect with changes in biogas yield or sugar beet prices, PSSB-25

Upgrading costs matter for the net-income as seen in Figure 4-2 and can be a critical option for achieving economies of scale. In our reference cases we assume that the plant upgrades when the biogas yield exceeds 3.5 mill $\mathrm{m}^{3}$ p.a., this may however not be the optimal solution. In order to compare the choice between direct use and upgrading we explore this with a sensitivity analysis for the $12.5 \%$ sugar beet case in relation to yield variations and scale. In the case of direct use, it is assumed that the heat demand is completely covered with a biogas supply of 3.5 mill $\mathrm{m}^{3}$ p.a. All biogas exceeding this level generates an electricity production which is supported, while all additional heat production is wasted (cooled). All biogas exceeding $3.5 \mathrm{mill}^{3}$ will thus receive a lover price only related to the electricity production. 


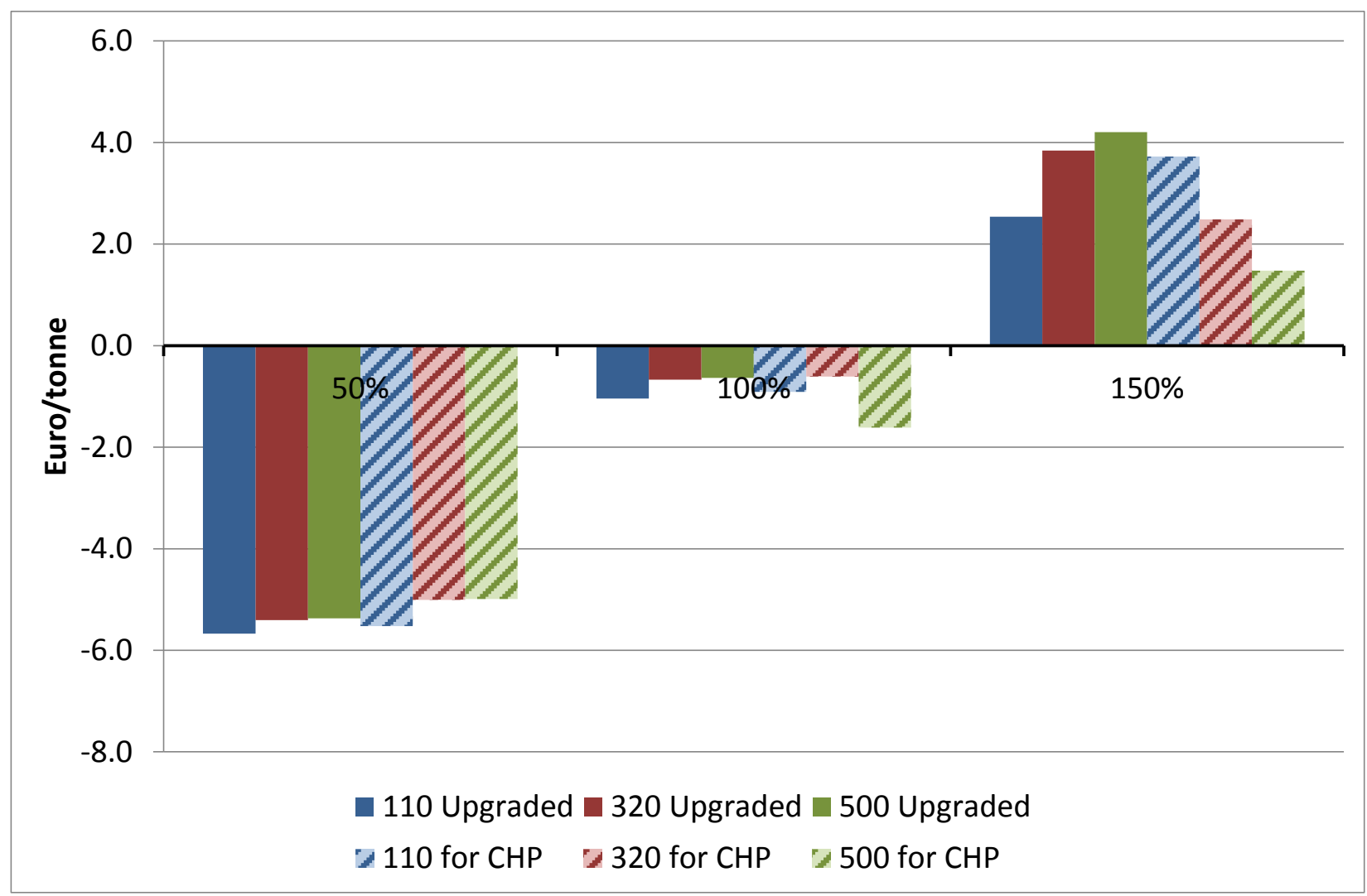

Figure 4-3: Sensitivity - Net income effect with changes in biogas yield depending on the choice to upgrade the biogas or direct usage in a local CHP, PSSB-12.5

Figure 4-3 illustrates the challenges for a biogas plant feeding into a local CHP with a limited heat demand. This challenge increases with scale as the risk of biogas excess supply increases, which then decreases the value of a higher than anticipated biogas yield. That yield is such an important factor is not surprising as two thirds of the income is based on the biogas yield and around two thirds of this is support. This shows the importance of focus on the yield, but also illustrates a clear risk associated with yield and changes in support.

On the cost side, the results are relatively robust towards changes in the individual cost factors. Only the sugar beet cost has a significant influence on the net income results. So, even though changes in costs can have a significant influence on net income, there is still potential to adjust other costs to achieve an improved net income, whereas the yield determines whether net income is positive or negative.

\section{Main risks associated with input prices, yield and output prices}

Managers of a biogas plant consider several risk factors when investing in technology and planning the operational strategy. In this paper, we focus on the risks associated with raw material inputs and output 
price/demand for biogas. The sensitivity analysis revealed some of the consequences from varying important parameters including input prices/costs and yield. We highlight the following risk elements:

- Sugar beet-price increase.

- Transport cost increase due to limited local availability of sugar beet.

- Technically poor performances of plant with low yield as a result - break-down and repair delays.

- Reduced yield due to varying/seasonal supply of co-substrates (sugar beet) and varying composition of primary input/manure.

- Output price variation (natural gas price excl. support) and fluctuating demand for heating from CHP plant - resulting in too low biogas demand and possible losses from flaring.

\subsection{Input cost elements}

The plant costs depend on changes in input prices and, in our case, specifically the sugar beet price for the cases with $12.5 \%$ and $25 \%$ sugar beet. A potential increase in the sugar beet price by up to $50 \%$ would have a severe impact on earnings (Figure 4-1 and Figure 4-2). This kind of price change is not entirely speculative, if the demand for sugar beet increases or supply decreases because farmers decide to grow more profitable crops. A parallel example could be the growth in demand for maize in Germany as the result of high biogas subsidies, adding a pressure on dairy farming (Jacobsen et al., 2014). The risk of fluctuations in the price of sugar beet in the future is serious and measures to reduce this risk or the effect of such price increases will have to be a focus of the biogas plant. Being dependent on only one secondary high-yield resource is risky. Therefore, measures that secure the technical use of alternative inputs and the availability of these can reduce the risks associated with input prices. A high price for sugar beet would call for a part/full substitution to other co-substrates as inputs and a more moderate cost increase on the input side. Flexible technology and the ability to substitute between co-substrates is a key strategy to reduce this risk element. One step could be to focus on waste products which are already common used at many biogas plants; this could be a cheaper and more sustainable solution. It can however also introduce other issues in terms of how to use the digestate containing waste products (Huttunen et al., 2014; Lantz et al., 2007) and already now the access to good waste products is reduced and prices have increased (Geels and Raven, 2007). 
The distance and, thereby, transport costs are also important (Figure 4-1), but the risk is probably lower than the risk of an increase in the sugar beet price. For manure, availability is relatively predictable and the resource is local so there is little competition regarding this input. Therefore, changes in livestock/pig populations would only increase the transport distance to collect manure gradually and with moderate increases in distance. One risk is that it would only be possible to use the same lorry to collect the manure and distribute back to the farmer directly to a limited extent, which would double the distance driven compared to our assumption.

For the secondary input, sugar beet, the transport costs are much higher per tonne and the resource is widely used with many alternatives. Our assumptions for distance are quite conservative (up to 80km), but the risk is still substantial if sugar beet has to be transported from other regions of Denmark. The probable solution would be to use another and closer substrate, so risk will here be reduced if the plant technically and legally can use a variety of co-substrates instead of only one.

The entire revenue for the biogas plant depends on the output level and, therefore, the biogas yield is one of the main risk factors as revealed in the sensitivity analysis (Figure 4-2). First, the general technology risk of the performance of the plant being lower than expected is a risk prior to investment. In particular, the lifetime of equipment along with necessary downtime for repair and cleaning will be risk factors regarding the realised annual yield. Using proven technology reduces this risk, but the use of different/flexible inputs necessitates the use of unproven technology to some extent. This is a major ex ante risk to the investment decision.

To optimise the yield, a steady input mix and controlled feeding with inputs of a constant quality is the best. The risk here is that the inputs will vary in availability and quality during the year/seasons (especially sugar beet which cannot be expected to have the same quality/availability throughout the year). This implies the risk that the average realised yield will be lower than the optimally controlled case. Also, the knowledge of the actual content and biogas potential of the inputs is not always perfect and, therefore, optimal feeding is not possible. The risks associated with lower yield due to these causes is probably less than the basic technology risk, but moderate assumptions of realised yield should be used. 


\subsection{Income risk elements}

As described in the methods section, income consists of income from sales of digestate and income from sales of biogas output (here both the biogas used directly and upgraded natural gas).

$$
\begin{aligned}
& I\left(p_{j}, M_{j}\right)=p_{\text {gas }} \cdot M_{\text {gas }}+p_{\text {digestate }} \cdot M_{\text {digestate }} \\
= & \left(p^{N G}+p^{g}+S_{\text {gas }}\right) \cdot M_{\text {gas }}+p_{\text {digestate }} \cdot M_{\text {digestate }}
\end{aligned}
$$

The natural gas price fluctuates and constitutes one risk element on the income side, but the market price $p^{N G}$ is only a smaller fraction of the biogas income, and this price risk can be hedged in the short to medium term. The support $\left(S_{\text {gas }}\right)$ on top of the gas price is an almost fixed premium and constitutes around $2 / 3$ of the revenue per biogas unit, which reduces the risk (variation) on the income side substantially, see more on this in appendix A. In the case of sales directly to a local CHP plant which does not use upgraded biogas, the price risk is higher as the support is provided for the electricity generation of the CHP plant. Therefore, there is no guarantee that the biogas price is directly tied to the support. For this reason, the solution is often to reduce risk for the biogas plant by negotiating a long-term fixed price for the gas used by the CHP plant. However, there is also a volume risk associated with the sales to a CHP plant. If the biogas output is dimensioned relative to the heat demand supplied by the CHP, seasonal variation in heat demand will result in varying demand for biogas throughout the year. This is critical to the risk actually faced by the biogas plant and can be expected to reduce the average income realised. The sensitivity analysis presented in Figure 4-3 further illustrates how the benefit of an extra yield increases with scale in the case of upgrading, whereas this benefit in fact decreases with scale when the biogas plant feeds directly into a local CHP with a predefined heat demand. In the long-term this risk can even be enhanced with structural changes if, for example, heat pumps, electric boilers or biomass boilers take over a larger fraction of the supply for the district heat grid and thereby even reduce biogas demand if heat demand decreases . This combination of a seasonal and long-term structural volume risk must be characterised as important and to some extent fundamental regarding the decision of whether to base a biogas plant on supply to CHP plants or to upgrade for input to the natural gas grid. 
The biogas plant also generates income from the digestate output of the plant. The risk associated with the part that is returned directly to the farmer who supplies the manure is limited as the contract with the farmer often ties the supply of manure with the return of the treated manure with fixed prices for both. As long as the farmer receives a higher value product than he supplies, the contract and, thereby, the income must be assumed to be associated with low risk. Farmers are, however, quite financially exposed (high debt ratios) which means that there is a risk that some of them may go bankrupt and the contracts may not be continued with the farmer who takes over. Furthermore, there is a volume risk as the farmers may change the composition of livestock/pigs and the size of their activities, while the amount of dry matter in the manure may also vary. The dry matter has a substantial effect on the biogas potential and, therefore, poses a considerable risk to the biogas income.

Finally, the main income source is the support level set by the authorities. There is always a risk element associated with this kind of public support. In this Danish case, the support is a fixed premium (upgraded gas), which must be seen as guaranteed by the general Danish government principle of never changing support provided to existing plants (investors). Indirectly, the authorities can, however, change the effective level of support by modifications to the fees for entering the grid, regulations/requirements for emissions from biogas plants, etc. but this risk can be characterised as relatively low and with very moderate potential impact.

\section{Regulatory implications}

We find that input cost and transport cost can have a significant influence on the profitability of the biogas plant. Investment in the biogas plant is profitable in our case based on current support policies. The cases with added sugar beet are not profitable under the assumptions of sugar beet prices, yield and transport distances, but they are attractive from the perspective of replacing fossil fuels in the energy sector. The biogas output level is much higher in these cases and based on the public policy for replacing fossil fuels (natural gas) with biogas and reducing GHG emissions, these cases have the greatest environmental benefit (Boldrin et al., 2016). The sensitivity analysis illustrated that the price of the co-substrate (sugar beet) is critical for profitability and the risk discussion pointed to the option of reducing the associated risk for the cost of the co-substrate. 


\subsection{Input mix alternatives should be allowed}

A biogas plant will be located close to a supply of manure, but it is also important to be located close to a cheap source of co-substrate. With the right pre-treatment and process, biogas plants can digest almost any co-substrate to increase the probability of profitable operations. In order to support flexibility and thereby profitability, regulation should set as few restrictions on the types of co-substrates as possible without undermining other objectives such as sustainability, food safety and the environment. Flexibility in the input mix will considerably reduce the risk associated with the co-substrate price, but also the risk regarding the necessary transport distances as a secondary benefit. If one co-substrate has to be collected from very far away to achieve the desired volume, the plant may choose to add an additional co-substrate even though its price is higher as its location is closer; thereby reducing transport costs so that the combined cost is competitive in relation to the first co-substrate. Current Danish regulatory policy limits the use of energy crops to $25 \%$ of total inputs, but in 2018 , this will be reduced to $12 \%$, which is the constraining factor for the design of new plants (Danish Energy Agency, 2012). This restriction does not seem critical in the cases analysed in this article as profitability in the $25 \%$ case is lower than in the 12.5 $\%$ case. However, there may be co-substrate shares in the range $12.5-25 \%$ that are more profitable, but not tested in our case. As already mentioned these co-substrates could be various waste products which are already used with great success in Denmark (Geels and Raven, 2007; Holm-Nielsen et al., 2009), in order to assure flexibility but also food safety we suggest a safelist on waste products, which can be used in biogas production without damaging the benefits and the reputation of the digestate (Huttunen et al., 2014).

\subsection{Yield focus is a result of support provided for end-use of biogas}

We find that the biogas yield has a significant influence on the net-income. Therefore, the focus of the plant is on maximising yield. Net income is dominated by the income from biogas, particularly from the biogas feed-in tariffs which account for approximately $40-50 \%$ of the total net income. The fact that public biogas support is provided primarily for biogas output has the following implications:

- The biogas plant will not use biogas for own process use at the plant

- Yield maximisation drives demand for high yield co-substrates 
- $\quad$ The incentive when upgrading to the natural gas grid is to maximise total annual biogas output

As mentioned in section 2.3, the support for biogas used in a local CHP is for the electricity output and a tax reduction on the heat produced from biogas. For a CHP plant supplied with biogas, there is an incentive to maximise biogas-based electricity production independently of power demand on the grid, only conditional on the steady supply of biogas and heat demand. This is inefficient for the power system, where conditions include hours with low electricity demand and correspondingly very low or zero electricity prices. A final indirect implication of the Danish biogas support system is that the farmer has no incentive to support a high biogas yield, but only has to comply with manure characteristic requirements from the biogas plant.

\subsection{Regulation, the choices of scale and whether to upgrade}

Until recently, support for biogas production was only available indirectly via support for electricity and heat production in a local CHP. Regulation has now been modified to include support at a comparable level for biogas supplied to the natural gas grid. This change towards a more flexible regulation affects both the ability to exploit economies of scale and the choice of whether to upgrade or not.

We find economies of scale and to exploit this, the biogas plant has to either find a large district heating market or upgrade the biogas. The large district heating market should be situated in an area with a sufficient concentration of manure resources to limit transport costs. These requirements are quite restrictive and would, therefore, often hinder the full exploitation of economies of scale; with upgrading to the gas grid the biogas plant becomes independent of a large heat demand. Furthermore the exploitation of economies of scale is dependent on sufficient available input, allowing several alternative co-substrates would increase biogas output with lower costs even in areas where manure is less concentrated, if only few co-substrates are allowed this may in itself be a barrier to exploiting economies of scale.

Upgrade is a way to exploit economies of scale and reduce the dependence on a monopoly CHP buyer of biogas. An essential assumption in our model is that upgrading is possible with support levels similar to support for use in CHPs. Before the recent change in regulation, CHPs were monopoly buyers of the biogas, which forced the biogas plants into long-term contracts with relatively low biogas prices. Furthermore, the biogas producer would have an increased risk of demand when the contract expired, which would set a heat demand determined limit on the optimal size of the biogas plant and prevent 
economies of scale. With support for upgraded biogas, the CHPs have lost the monopoly power and the biogas producer has an improved better chance to benefit from economies of scale.

\section{Conclusion and Policy Implications}

In this Danish case study, we find that per unit transport costs for biogas plants increase with scale, which partly offsets the economies of scale found for capital and operational expenditures. A detailed modelling of available manure resources, the fixed and variable transport costs and digestate transport costs suggests that in certain areas of Denmark, centralised large-scale biogas plants are the most economical; provided that all biogas production can be upgraded to the natural gas grid and receive the available support.

When the biogas plant size is scaled up from 110,000 tonnes of annual inputs to 500,000 tonnes, the opposing contributors to scale effects and the net result found are:

- A unit cost reducing effect in capex and opex, where unit costs are reduced by $16-18 \%$.

- A unit cost increasing effect from transport, with an increase of $45 \%$ for manure input and $47-65 \%$ for sugar beet input.

- For the $100 \%$ manure case, the net effect (trade-off) is a total unit cost reduction of $6 \%$.

- For the two cases with sugar beet, the net effect is a slight increase in unit cost, where the economies of scale disappear due to faster rising sugar beet transport costs and output related costs.

The regulatory choices made by the authorities both concerning the level of support for biogas and the enduse options supported are crucial for the profitability of biogas production and also for providing incentives for choosing the most efficient scale and inputs for operation.

Scale effects favour the choice of upgrading to natural gas quality as the biogas production becomes independent of local demand, both in relation to scaling of the plant, production variations and the risk of a decreasing and varying heat demand.

Additionally, the assumption that the entire subsidy for biogas used in the CHP plant accrues to the biogas plant is questionable for alternative ownership structures. We have assumed that either the CHP owns and builds the biogas plant as an additional activity or that the negotiating power of the biogas plant is sufficiently strong to secure the full subsidy. Alternative assumptions may further change the 
attractiveness of upgrading relative to the CHP solution, and authorities have to carefully consider both the level of support provided, but also differences in support for different end uses of biogas.

The sugar beet price and biogas yield were identified as critical assumptions for the results and sensitivity analysis carried out for these elements. We can conclude that there is a case for larger scale biogas plants in Denmark based on economies of scale regarding costs, but that the effect of co-substrates such as sugar beet requires availability relatively close to the plant combined with a low price for the co-substrate or a higher biogas yield. Alternatively other co-substrates could be considered emphasising the need for flexible input options as for example waste products in order to keep transport and substrate costs down and the yield up.

\section{Acknowledgements}

The authors wish to thank the three anonymous reviewers for valuable insights and suggestions. The authors also wish to acknowledge the support given by the Innovation foundation under the "Strategic Research in Sustainable Energy and Environment” research programme (grant no. 12-132631) to the project "Optimisation of value chains for biogas production in Denmark (BioChain)”. 


\section{References}

Abildgaard, L., 2015. Personal Communication with SEGES.

Australian Meat Processor Corporation, 2013. Fact Sheet - Biogas quality \& cleaning technology 3.

Bauer, F., Persson, T., Hulteberg, C., Tamm, D., 2013. Biogas upgrading - technology overview, comparison and perspectives for the future. Biofuels, Bioprod. Biorefining 7, 499-511. doi:10.1002/bbb.1423

Boldrin, A., Baral, K.R., Fitamo, T., Vazifehkhoran, A.H., Jensen, I.G., Kjærgaard, I., Lyng, K.-A., van Nguyen, Q., Nielsen, L.S., Triolo, J.M., 2016. Optimised biogas production from the co-digestion of sugar beet with pig slurry: Integrating energy, GHG and economic accounting. Energy 112, 606-617. doi:10.1016/j.energy.2016.06.068

Brudermann, T., Mitterhuber, C., Posch, A., 2015. Agricultural biogas plants - A systematic analysis of strengths, weaknesses, opportunities and threats. Energy Policy 76, 107-111.

COWI, 2013. Business case for biogasanlæg med afsætning til naturgasnettet, in English: "Business Case for Biogas with sales to the natural gas network."

Danish Energy Agency, 2016. Support for biogas https://ens.dk/ansvarsomraader/bioenergi/stoette-tilbiogas.

Danish Energy Agency, 2012. Begraensning for brug af majs og andre energiafgrøder til produktion af biogas, J.nr.3401/1001-4491, in English: "Memorandum on use of energy crops."

Danish Parliament, 2012. 2011/1 LSV 182: Lov om ændring af lov om fremme af vedvarende energi, lov om elforsyning, lov om naturgasforsyning og lov om Energinet.dk, in English: "Law on the promotion of Renewable Energy, electricity supply, natural gas supply and Energinet.dk."

Deloitte, 2013. Afdækning af muligheder for at fremme investeringer i biogas, in English: "Uncovering opportunities to promote investments in biogas."

Delzeit, R., Kellner, U., 2013. The impact of plant size and location on profitability of biogas plants in 
Germany under consideration of processing digestates. Biomass and Bioenergy 52, 43-53.

Ea Energianalyse, 2014. Anvendelse af biogas til el- og varmeproduktion, analyser for biogas taskforce, in English: "The use of biogas for electricity and heat."

Geels, F.W., Raven, R.P.J.M., 2007. Socio-cognitive evolution and co-evolution in competing technical trajectories: Biogas development in Denmark (1970-2002). Int. J. Sustain. Dev. World Ecol. 14, 6377.

Hjort-Gregersen, K., Blandford, D., Gooch, C.A., 2011. Biogas from Farm-based Biomass Sources Developments in Europe and the US Le biogaz dérivé de la biomasse d'origine agricole Développements en Europe et aux États-Unis Biogas aus Biomasse von landwirtschaftlichen Betrieben Entwicklungen in Europa und d. EuroChoices 10, 18-23.

Holm-Nielsen, J.B., Al Seadi, T., Oleskowicz-Popiel, P., 2009. The future of anaerobic digestion and biogas utilization. Bioresour. Technol. 100, 5478-84. doi:10.1016/j.biortech.2008.12.046

Huttunen, S., Kivimaa, P., Virkamäki, V., 2014. The need for policy coherence to trigger a transition to biogas production. Environ. Innov. Soc. Transitions 12, 14-30. doi:10.1016/j.eist.2014.04.002

Jacobsen, B.H., Laugesen, F.M., Dubgaard, A., 2014. The economics of biogas in Denmark. Int. J. Agric. Manag. 3, $135-144$.

Jacobsen, B.H., Laugesen, F.M., Dubgaard, A., Bojesen, M., 2013. Biogasproduktion i Danmark Vurderinger af drifts- og samfundsøkonomi, in English: "Biogas production in Denmark Assessments of private and socio economy," Institut for fødevarer- og ressource økonomi. IFRO Rapport 220, Fredriksberg.

Lantz, M., Svensson, M., Björnsson, L., Börjesson, P., 2007. The prospects for an expansion of biogas systems in Sweden-Incentives, barriers and potentials. Energy Policy 35, 1830-1843. doi:10.1016/j.enpol.2006.05.017

Lebuhn, M., Munk, B., Effenberger, M., 2014. Agricultural biogas production in Germany - from practice 
to microbiology basics. Energy. Sustain. Soc. 4, 10. doi:10.1186/2192-0567-4-10

Lemvig biogas, plant, 2016. Digestate: http://lemvigbiogas.com/gylle.htm.

Lybæk, R., 2014. Use, Operation and Maintenance of Renewable Energy Systems, Use, Operation and Maintenance of Renewable Energy Systems, Green Energy and Technology. Springer International Publishing, Cham.

Mafakheri, F., Nasiri, F., 2014. Modeling of biomass-to-energy supply chain operations: Applications, challenges and research directions. Energy Policy 67, 116-126. doi:10.1016/j.enpol.2013.11.071

Nielsen, L.H., Hjort-Gregersen, K., 2002. Socio-economic Analysis of Centralised Biogas Plants.

Patterson, T., Esteves, S., Dinsdale, R., Guwy, A., 2011. An evaluation of the policy and techno-economic factors affecting the potential for biogas upgrading for transport fuel use in the UK. Energy Policy 39, 1806-1816. doi:10.1016/j.enpol.2011.01.017

PlanEnergi, 2014. Beslutningsgrundlag for Grøn Gas Investeringer, in English “Decision paper for Green Gas Investments."

Raven, R.P.J.M., Gregersen, K.H., 2007. Biogas plants in Denmark: successes and setbacks. Renew. Sustain. Energy Rev. doi:10.1016/j.rser.2004.12.002

Skovsgaard, L., Klinge Jacobsen, H., 2015. Economies of scale in biogas production. IAEE Energy Forum $31-32$.

Tafdrup, S., 2010. Økonomien i biogasprojekter, sammenhæng med st $\varnothing$ ttesatser i forhold til substitueret brændsel og andre forhold; J.nr. 3401/1001-2255, in English: “Economy for biogas related to support, substituted fuel and other."

Walla, C., Schneeberger, W., 2008. The optimal size for biogas plants. Biomass and Bioenergy 32, 551-7. doi:10.1016/j.biombioe.2007.11.009

Yabe, N., 2013. Environmental and economic evaluations of centralized biogas plants running on cow manure in. Biomass and Bioenergy 49, 143-151. doi:10.1016/j.biombioe.2012.12.001 


\section{Appendix A: Key data}

Data for the model have primarily been found in Danish biogas literature estimated from public and less public data and collected in the BioChain project, see Acknowledgements.

\section{Scale}

Scale is represented in the form of mass input, which is typical for Danish analyses with most cost data being related to input size in tonnes. The input mix varies in the different cases as does the output in energy content. Therefore, the stable capacity factor is tonnes of input. Other analyses around Europe relate to energy output in the form of $\mathrm{kW}_{\mathrm{el}}$ capacity which makes sense as regulation in most European countries is related to output in the form of $\mathrm{kWh}_{\mathrm{el}}$ (Hjort-Gregersen et al., 2011). Under the new Danish regulation, which was finally ratified in spring 2014, biogas support was equalised regardless of whether biogas is upgraded for the gas net or cleaned for use in a local CHP. Furthermore, the support is independent of scale, contrary to biogas support given in other European countries such as Austria and Germany, (Brudermann et al., 2015; Lantz et al., 2007)

Three different plant sizes are investigated. Small(110) with a capacity of 110,000 tonne of biomass input p.a., Medium(320) with a capacity of 320,000 tonne and Large(500) with a capacity of 500,000 tonne. Plant size has been decided on the grounds of history, the size used in other analyses and future expectations in Denmark. The plant is considered as a centralised plant and the small scale (110) can be considered relatively large-scale compared to the sizes dealt with in both Delzeit and Walla who consider electricity capacities up to 1MW (Delzeit and Kellner, 2013). Depending on the input mix, our small scale (110) plant could feed into a CHP plant of the size of 0.5-1 $\mathrm{MW}_{\mathrm{el}}$. The Medium (320) size case is considerably larger and corresponds to a size which is often used in Danish analyses and is relatively typical for a Danish central plant (COWI, 2013; Deloitte, 2013; Ea Energianalyse, 2014). Only a few large-scale (500) plants have been built, but several plants of this size have been planned for the future. As support is independent of size in Denmark, plants even larger than 500,000 tonne have been built in Denmark. 


\section{The output related costs}

The output related costs are the sum of biogas treatment costs, storage and transport. The chosen technology for biogas cleaning is biological trickling filter and water scrubber for the biogas upgrading, water scrubber is a widely used technology se e.g. (Patterson et al., 2011). Depending on the size of the biogas yield, the model can choose between three different treatment sizes (Australian Meat Processor Corporation, 2013; Bauer et al., 2013). Again we find scale effects as unit costs decreases as the gas amounts increases. Storage costs relates to the biogas storage with a capacity which corresponds to one day of production - allowing temporary storage in cases where the biogas is polluted; and storage of digestate that cannot be returned to the animal farmer immediately. Only in the PSSB-25case, where sugar beet input is $25 \%$, will some of the digestate be sold to other parties (plant farmers). In this case, additional costs are added as the extra digestate has to be stored at the plant until spring, when it can be delivered to the plant farmers. Transport costs for biogas include pipe and compression costs; assuming that the connected CHP and the distribution net is situated only $1 \mathrm{~km}$ from the biogas plant.

The scale effect within the upgrading technology is illustrated by the figures in Table A -1.

\begin{tabular}{l|lll}
\hline Ratio/Scale & 110,000 & 320,000 & 500,000 \\
\hline Gas, Cleaning for CHP & 0.15 & 0.15 & 0.08 \\
Gas, Upgrading for the net & - & 0.89 & 0.55 \\
\hline
\end{tabular}

Table A -1: Investment and operational costs associated with treatment of gas for upgrade or CHP, Euro/tonne of input

From the table, it is also apparent that there is a substantial difference in costs depending on whether gas is cleaned or upgraded. In this model, upgrading seems less attractive to the biogas producer, due to the higher treatment costs, combined with the assumption that price and support is almost independent of whether the gas is upgraded or cleaned for local use; similar results was found in (Jacobsen et al., 2014)

\section{Yield}

\begin{tabular}{l|ccc}
\hline & PSSB-0 & PSSB-12.5 & PSSB-25 \\
\hline Biogas yield (70\% NH4) & 12.6 & 17.1 & 25.0 \\
Bio-methane yield (98\% NH4) & 9.0 & 12.2 & 17.8 \\
\hline
\end{tabular}

Table A-2: Biogas Yield, cubic metres biogas per tonne of input

The biogas yield has been estimated from our project partners in the Biochain project on the basis of micro-experiments with pig manure combined with sugar beet pulp in different ratios. From these 
experiments, we also experienced that the results become difficult to use when the percentage of sugar beet exceeds 25\% (Boldrin et al., 2016).

\section{Prices}

\begin{tabular}{l|cccc|r}
\hline & Basis price & Support & Green value & Manure price & Total price \\
\hline Sugar beet, Euro/tonnes & 27.46 & & & & 27.46 \\
Digestate, Euro/tonnes & 10.05 & - & - & -6.03 & 4.02 \\
Bio-methane, Euro/NM3 & 0.26 & 0.55 & 0.02 & & 0.83 \\
Biogas CHP, Euro/NM3 & 0.26 & 0.55 & & & 0.81 \\
\hline
\end{tabular}

Table A -3: Prices in Euro/tonnes and Euro/M3 Biomethane

The Sugar beet price is given by SEGES and the price is estimated for sugar beet pulp/sliced sugar beets. This price is close to the production cost of Sugar beet, and according to SEGES this price has been constant for a long while (Abildgaard, 2015). Input and output prices for manure/digestate are also given by SEGES (Abildgaard, 2015) and are based on prices negotiated between the animal farmers and the biogas plant. There is both a price on manure and digestate, but the prices used for the calculations are the digestate and net-digestate prices (digestate price minus manure cost). The digestate price corresponds to the fertilizer value of the digestate (see for example (Lemvig biogas, 2016) ) and the net-digestate price can be interpreted as the value added through the biogas process. The interlinkage between digestate price and manure costs implies our focus on the net-price of digestate. This also corresponds to models used elsewhere se for example (Jacobsen et al., 2014). The pricing of manure and digestate vary among biogas plants, depending on where they are situated.

Biogas prices are calculated on the basis of the official feed-in tariffs and results from the Biogas Taskforce analysis on the expected basis price plus the expected green value (PlanEnergi, 2014). The feed-in tariff consists of three parts; 1) approximately $70 \%$ of the subsidy is without any time limit and indexed following $60 \%$ of inflation, 2) approximately $20 \%$ of the subsidy is also without a time limit and is negatively correlated with the gas price - thereby reducing the risk of income loss related to the natural gas price, and finally 3) approximately $10 \%$ of the subsidy is phased out in the period from 2015-2020 (Danish Energy Agency, 2016). This basically means that support is expected to decrease to some extent, however with a high certainty, so income losses on this account can be included in the calculations from the start. 
As argued in section 2.3 and 5.2, it is debatable whether the biogas plant can expect the same price for the biogas when it is sold directly to the local CHP as if it was upgraded. This counts both for the natural gas price but also the expected share of the subsidy. The green value only relates to the case of upgrading, but this value is not considered to be high. The authors of "GGI" from blue energy planet have found indications of willingness-to-pay in the region of 1-10 Eurocent/NM3. When asked directly, however, they expect a price in the lower end of this range. The estimated value is uncertain, but is close to the current value of the $\mathrm{CO}_{2}$-quota price, and therefore the best approximation we could achieve given the currently lack of an open market for green certificates in Denmark.

\section{Appendix B: Additional sensitivity graphs}

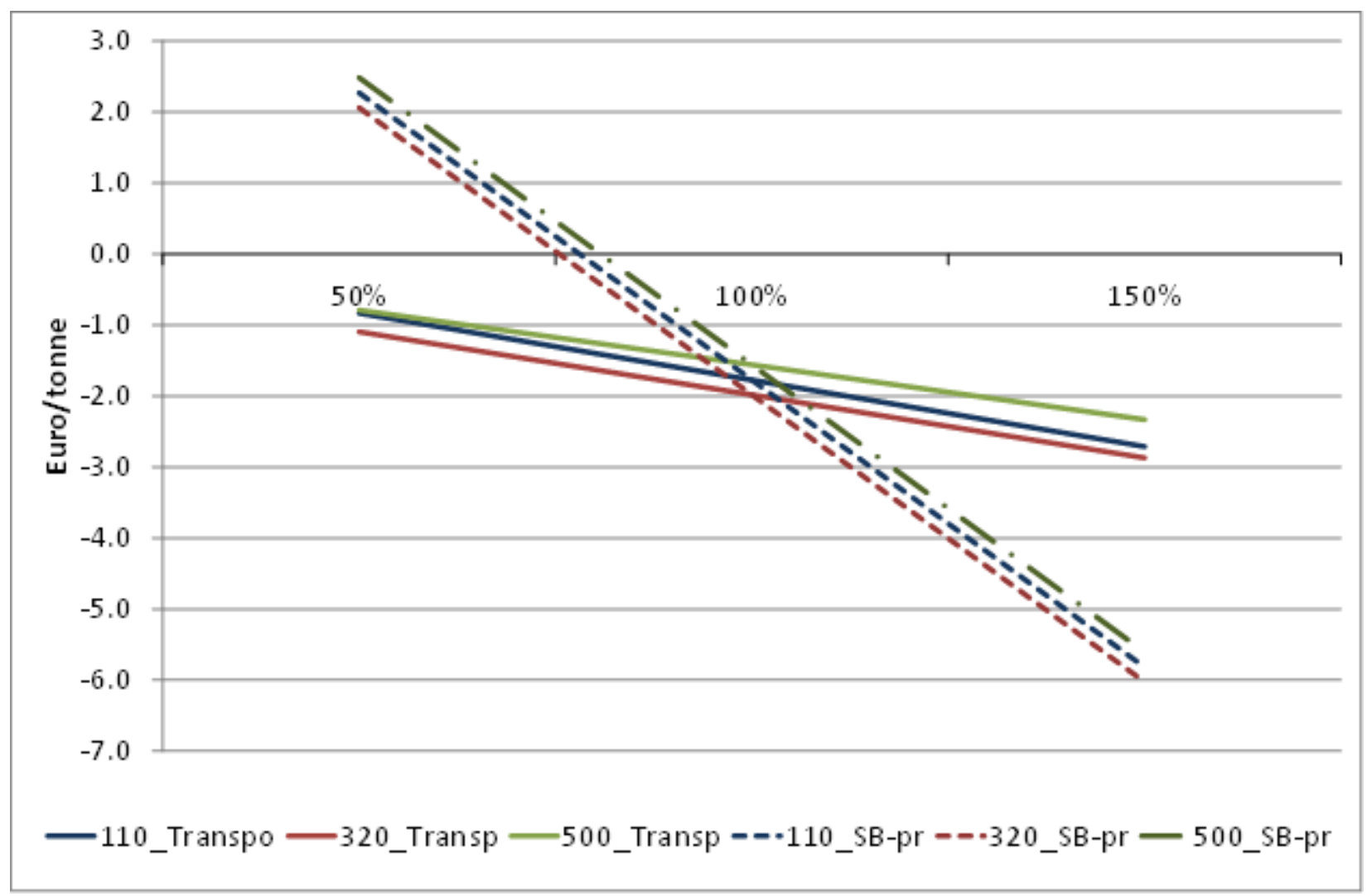

Figure B-1: Sensitivity on transport costs and sugar beet prices, PSSB-25 


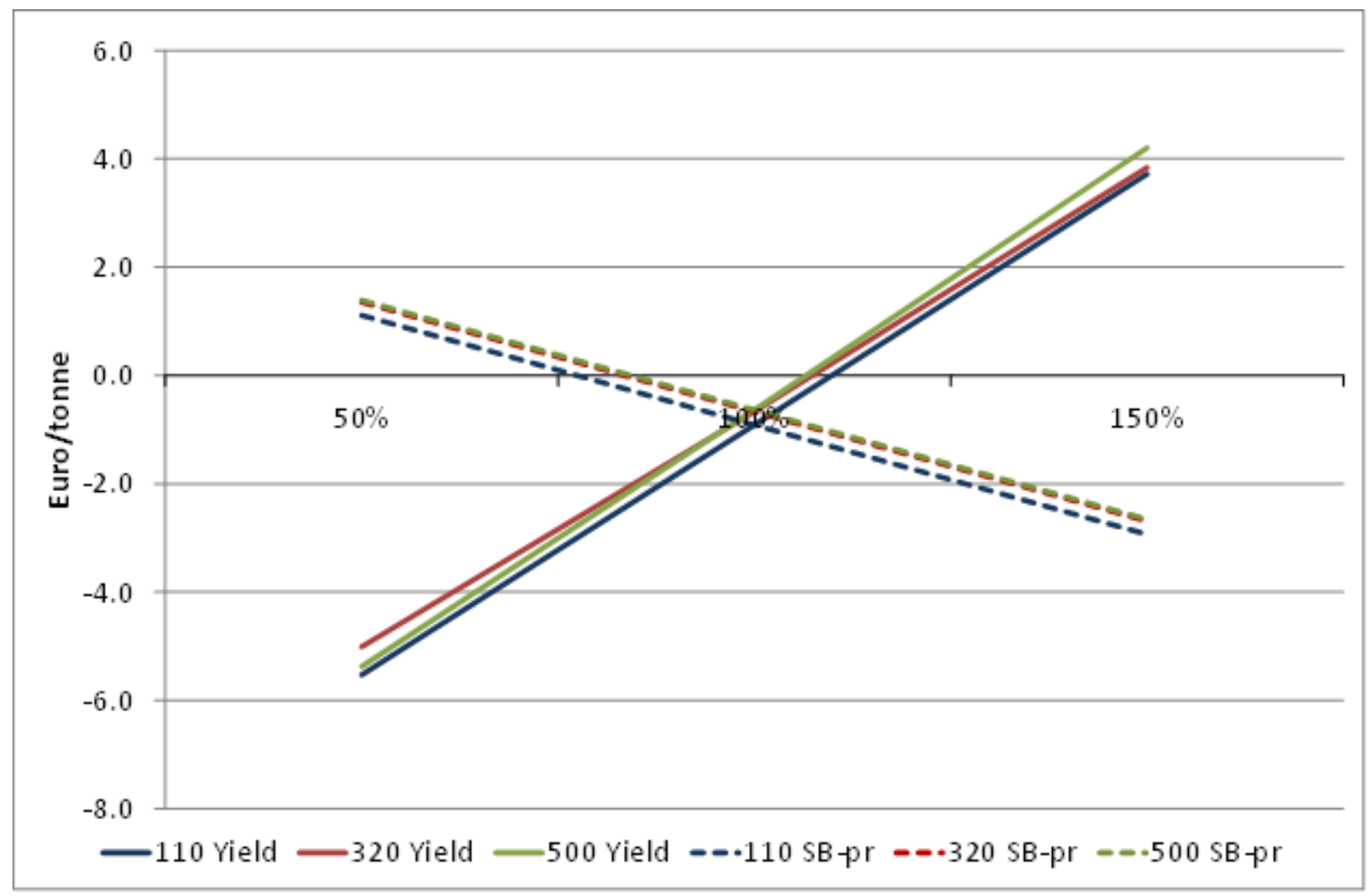

Figure B-2: Sensitivity on sugar beet prices and Yield, PSSB-12.5 